Roberto Osorno Hinojosa, Ph.D. in Economics, Senior Researcher of the Department of Electronics, Systems and Informatics at the Instituto Tecnológico y de Estudios Superiores de Occidente (ITESO) (Tlaquepaque, Mexico)

Delia del Carmen Ramírez Vázquez, MBA, Researcher of the Department of Electronics, Systems and Informatics at ITESO (Tlaquepaque, Mexico)

Hilda Shari Gómez Romero, Service Enterprise Engineer at ITESO (Tlaquepaque, Mexico)

Ariadna Itzel Ramírez Vázquez, Student of the Service Enterprise Engineering at ITESO (Tlaquepaque, Mexico)

Andrea Juvera Brooks, Student of the Service Enterprise Engineering at ITESO (Tlaquepaque, Mexico)

\title{
ACTORS AND MOTIVATORS IN OPEN INNOVATION PLATFORMS
}

\begin{abstract}
The way innovation is know has started to change, shifting from a closed to an open approach. Open innovation has been creating new ways of working in innovation ecosystems, giving the actors more opportunities to obtain new tools, knowledge and more benefits by collaborating with other actors involved in the same network. These innovation ecosystems have their support on innovation platforms, which have different rules and protocols that describe the way interaction should take place. Based on this, this work is motivated in knowing why actors would participate in open innovation platforms.

The approach for this paper is to define the motivators and interests of the actors -Government, Businesses and Universities- in their participation in open innovation platforms, as well as to represent how this can benefit them. A case is presented in which the motivators and actors are related in an ecosystem, indicating how they take advantage of the knowledge and resources in it.
\end{abstract}

Keywords: open innovation, innovation platforms, innovation ecosystems, co-creation, motivators, and actors.

\section{Introduction}

Nowadays, the traditional way of working of many institutions: enterprises, schools, government, or others, is being left behind, replaced by a strong trend toward innovation ecosystems. In these ecosystems, the institutions can be seen as actors that play an important role by actively working hand-in-hand with other actors to achieve certain goals. These relationships are valuable since 
they bring enormous benefits not only to their participants but also to the whole society. Open innovation is a growing and developing trend in innovation ecosystems, offering more open processes, ideation and collaboration [Antikainen, Ahonen, 2010]. The term refers to the use of internal and external resources, such as knowledge and ideas, to speed up innovation and expand markets by using external innovation [Chesbrough, 2006].

However, this trend is just starting and there are things to be understand about these ecosystems. An interesting question here is why these actors might be interested in participating in an open innovation platforms.

Based through the research on diverse authors, this paper seeks to understand the main factors that motivate certain actors to collaborate in an innovation platform.

To achieve that, first it is presented the theory related to the question, after that a case related to open innovation platforms is present where a discussion is made. Finally, conclusions and recommendations are offer.

\section{Theoretical Framework}

The following text describes the main concepts used in this paper with the purpose of having a clearer vision of the generic concept.

\subsection{Ecosystems}

There are numerous definitions of different types of ecosystems in management, economics, and business literature. According to Iansiti, M. and Levien, R. [2004], an ecosystem is "a community of interacting entities that co-evolve their capabilities and roles and depend on one another for their overall effectiveness and survival."

Lusch, R. F. and Nambisan, S. [2015] define a service ecosystem as a "relatively self-contained, self-adjusting system of mostly loosely coupled social and economic (resource-integrating) actors connected by shared institutional logics and mutual value creation through service exchange".

\subsection{Innovation Ecosystems}

A system of innovation can be defined as "all important economic, political, social, organizational, institutional and other factors that influence the development, diffusion and the use of innovations" [Chaminade, Edquist, 2006] Innovation Ecosystems in turn can be define as a "network of interconnected organizations, connected to a focal firm of a platform, which incorporates both production and use side participants and creates and appropriates new value through innovation" [Autio, Thomas, 2014]. These types of ecosystems are also "collaborative 
arrangements through which firms combine their individual offerings into a coherent, customerfacing solution. Enabled by information technologies that have drastically reduced the costs of coordination, innovation ecosystems have become a core element in the growth strategies of firms in a wide range of industries" [Adner, 2006].

There are at least two types of innovation ecosystems. The first one is institutional, in which knowledge and resources are transfer in a linear manner with fixed relationships. The second one is call loosely coupled and consists of a dynamic constellation among actors without fixed patterns of relationships [Akaka, Vargo, 2014]. As seen, an innovation ecosystem needs support at different levels or layers depending on the kind of relationship that the actors are establishing.

\subsection{Platforms}

Open innovation is usually perform in networks and ecosystems in which actors interact to create value they co-create. The intermediation of platforms in the ecosystem is mention by Battistella, C. et al., [2017] and defines them as a place that enhances connections between enterprises and organizations, to share knowledge and solve problems.

Platforms are "modular structures that consist of tangible and intangible components and facilitate the interaction of actors and resources" [Lusch, Nambisan, 2015]. They support ecosystems' performance and are recognize as an important player in their competitiveness [Gawer, Cusumano, 2014].

Since co-creation requires resource integration among actors in the ecosystem, platforms must provide rules or protocols for exchange, an architecture for participation and a modular architecture that allows relationships to be integral and flexible. Platforms must give access to information, reduce cognitive distances and provide a shared worldview [Lusch, Nambisan, 2015].

Whether they are physical or digital, platforms enhance actor participation [Storbacka et al., 2016] and have a positive effect on innovation; they can also trigger the creation of new networks and ecosystems [Sedera et al., 2016].

Designing and implementing open innovation platforms presents different types of challenges, attraction and motivation of actors are two relevant ones identified in the literature [Rayna, Striukova, 2015; Rayna et al., 2015; Romero, Molina, 2009].

\subsection{Open Innovation}

The way businesses and other entities have traditionally worked is by developing and commercializing products, services and technologies with internal knowledge and capabilities; 
this way of working is known as closed innovation [Chesbrough 2006; van de Vrande et al., 2009]. This paradigm has been functional for several years, but nowadays businesses are no longer able to develop their own innovations due to different factors, such as "labor mobility, abundant venture capital and widely dispersed knowledge across multiple public and private organizations" [van de Vrande et al., 2009]. In the face of these obstacles, a new work perspective has emerged - open innovation.

As Chesbrough, H.W. [2006] establish, open innovation "combines internal and external ideas into architectures and systems whose requirements are defined by a business model that uses internal and external ideas to create value, while defining internal mechanisms to claim some portion of that value".

Open innovation is in some way the opposite of traditional innovation, while traditional innovation seeks experts whom usually work in specific areas inside the company commonly called research and development (R\&D), dedicated to create new products and services, which are later release to the rest of the company. Open innovation has an opposite essence, starting by opening the company and looking for experts outside without trying to place them inside the organization. Put into a single sentence, open innovation is "the use of purposive inflows and outflows of knowledge to accelerate internal innovation and expand the markets for external use of innovation" [Chesbrough, 2006].

\subsection{Co-creation}

The term co-creation has been use to refer the integration of diverse dynamic resources, in hope that value will be created. As Vargo, S. L. and Lusch, R. F. [2006] established, "There is no value until an offering is used - experience and perception are essential to value determination". In value co-creation, value is ultimately derived with the participation of the beneficiary (often, the customer), who determines the value through use (often called "consumption") in the process of acquisition, usage, and disposal [Holbrook, 1987].

\subsection{Actors in Ecosystems}

This innovation ecosystems approach is based on four key pillars [Carayannis, Campbell, 2012] government, business organizations, universities, and civil society. For the purpose of this paper, the focus is on the first three actors and the factors that could motivate them to participate in an open innovation platform.

Beginning with government, as an actor it has the goal of enriching the expertise of external stakeholders; therefore, the flow of knowledge needs to be clear and fluent, generating the know-how and tools that enable the stakeholders to collaborate among themselves 
[Antikainen, Ahonen, 2010]. This actor leads in motivating society to participate in open innovation and open collaboration; this means their main interest and guidance is the other stakeholders' participation. “Open collaboration is becoming the default place to start new projects" [Lathrop, Ruma, 2010].

Many governments have focused on engaging, seeking collaboration and participation as a way of improving and facilitating processes and consultations [Harrison et al., 2012]. By targeting innovation ecosystems, the intention of the government is to support and nurture them through direct or indirect contact.

As for the second pillar, businesses are looking for improvement, innovation, new technologies, with the aim of discovering new ways to develop products-services that will satisfy different needs in society. Many studies have been made, related to how open innovation could work for large businesses and what effects it has on them, but little research has been made on the benefits of open innovation for SMEs [Spithoven et al., 2012].

SMEs represent "a significant driver for the economic growth" [Gronum et al., 2012]. Spithoven et al., [2012] observe that, according to the National Science Foundation, SMEs have had an impact on industrial R\&D, having a growth in the USA from 4.4. \% in 1981 to $24.1 \%$ in 2005. Additionally, 33.7\% of the SMEs in the European Union are introducing innovation in their products, processes and services [European Commission 2009]. In addition, collaboration between large businesses and SMEs has helped these small and medium enterprises to expand further [Aris, 2007].

Finally, universities are an important actor when it comes to education, of course, since they are the ones in charge of enabling learning and helping other actors to take this learning and other knowledge into applied practice.

Society needs people that are capable of understanding, processing, and creating knowledge and putting it into practice. "This capacity can and should be supported by information and communication technologies, but it resides first and foremost in people's ability to think and to apply thinking skills effectively. Universities, in their core capacity of facilitating learning, are essential for this approach to be effective" [Markkula, Kune, 2015].

\section{Actor Motivators}

Next, the main factors are present, obtained through the research that could motivate the actors mentioned before - government, businesses and universities - to be part of an open innovation platform. 


\subsection{Government}

Government, as one of the main actors, has developed a new perspective in innovation and participation. Its role is based on increasing citizens', industries' and organizations' participation and this can be achieved through "policy means and instruments such as the regulatory environment, entrepreneurship education and awareness, access to finance and tech exchange, innovation and networking" [Fuerlinger et al., 2015]. The development of opportunities inside a country's economy has a positive influence on economic growth, thus the importance of promoting innovation ecosystems, promoting and supporting communication and transparency, and facilitating resources for the stakeholders involved [Feld ,2012].

Government as an entity focuses on the role of offering support through entrepreneurship and innovation programs, as well as incubator facilities, with the objective of connecting the different actors involved; this has a basis in funding and developing technology. "In recent decades, federal, state and local governments have created a variety of mechanisms to encourage knowledge-based economic development" [Etzkowitz, 2011].

\subsubsection{Openness and Transparency}

Among the government's main motivators to participate in open innovation are openness itself and transparency. The main example seen nowadays of how to reach these goals is the open government model that countries are adapting. Open Government Performance has a four-stage structure: stage one- increasing data transparency, stage two- improving open participation, stage three- enhancing open collaboration, and stage four- realizing ubiquitous engagement [Lee, Kwak, 2011].

With regard to transparency as one of the government's main principles and motivations, it is a means to reach openness, which results from the participation of the society involved. Initiatives are committing to the transparency movement, which triggers greater openness inside the government and helps develop strategies that engage citizens so they can take advantage of this movement [Lathrop, Ruma 2010]. Transparency in the data and information provided by citizens satisfies the public's basic needs for feeling that they are part of the process, such as at the level of co-creation among actors; this then becomes a basis for open participation and collaboration of the public and other external constituents and stakeholders [Fuerlinger et al., 2015].

\subsubsection{Communication and Facilitation}

Aiding communication between the actors is a critical step to establish a meaningful relation with the collaborators involved in the open innovations process. In order to generate a proper 
open participation of the public, communication must be an especially influential motive; adapting public engagement in the form of interactions through platforms and ecosystems helps connect people and helps them share their ideas. At the same time, it is important to focus on open collaboration, which means public engagement in a project that aims at a goal, through different support platforms that support integration and co-creation [Lee, Kwak, 2011].

A key factor of the government is to facilitate the relations it generates among the different actors involved in the process; each project at some stage of the innovations will cross paths with the governing body of its surroundings. One of their essential jobs is to expedite the support and promote the innovation. That said, "the government should not overestimate its potential for creating a self-sustaining entrepreneurship ecosystem and should rather act as a supporting force (“feeder"), rather than leading the movement" [Fuerlinger et al., 2015].

\subsubsection{Organizations', Businesses' and Citizens' Participation}

As mentioned before, the government's initiatives in open innovation consists of actively seeking participation from citizens and diverse stakeholders. "Governments must hone their capacity to integrate skills and knowledge from multiple participants to meet expectations for a more responsive resourceful, efficient and accountable form of governance" [Lathrop, Ruma, 2010].

Correspondingly, the government has to maintain the interest and participation of citizens and businesses; to generate growth in the economy it must focus on getting more people involved in open innovation, mainly the young and highly educated. The government plays an important role in motivating universities and businesses by opening access to finance, and public research funding [Fuerlinger et al., 2015].

When studying and researching these stakeholders, it is meaningful to recognize the importance of the exchange of technology and ideas as well as networking. As Fuerlinger, G. et al., [2015] say, the "key elements of a healthy innovation ecosystem are the links between different elements of that system."

\subsection{Businesses}

Nowadays, businesses need not just to focus on their internal knowledge and capacities, but to lead their exploration down different paths, such as external information from competitors and partners. SMEs usually lack certain resources (e.g. information, knowledge, financial and human resources, technology) for the development of new products and services; for this reason, SMEs are more involved in opening their innovation processes [Gronum et al., 2012]. 
However, even though industries are realizing that open innovation can be a path for improving their innovation and research processes, including their core business, there are still some doubts about the benefits of getting involved in an Open Innovation Platform, collaborating with other partners and entities, and sharing information and relevant aspects from their industries. This observation is made by Chesbrough and Appleyard, M. M. [2007], who stress that some experimenters -enterprises applying open innovation- are having certain issues with value capture and the sustainability of their business model.

In view of these doubts, this paper undertake research on different motivators that would lead businesses to participate in these platforms. According to the literature, there are five principal factors that could become a benefit: External knowledge (Outside-In), Revenues [Inside-Out], Resources for superior functionality, Complementary skills, and Reduction of risks. In addition, Cheng, C. C. J. and Huizingh, E. K. R. E. [2014] mention three types of activities in Open Innovation: outside-in activities, inside-out activities, and coupled activities. Outside-in activities are those that involve bringing external knowledge, resources, and technologies from external partners, to complement different aspects inside the business. On the other hand, there are the inside-out activities, which involve sharing knowledge, technologies and resources with other parties. Finally, coupled activities, which are the combination of the other two, creating collaborations and alliances between different partners.

It is explained next how both elements, the principal factors and the types of activities relate together to create the potential motivators.

\subsubsection{External Knowledge factor (Outside-in)}

According to Service-Dominant Logic, economies are no longer base on the product that is deliver at the end, but on the exchange of processes, skills and capabilities that a business can offer to other parties [Lusch, Nambisan, 2015]. In the same way, van de Vrande et al., [2009] stress that "work has become more knowledge-based and less rigidly defined." Because they are not able to gather knowledge about everything, businesses are no longer in the position of innovating and moving forward with exclusively internal know-how [Gronum et al., 2012]. Thus, they need to acquire the missing knowledge [van de Vrande et al., 2009] from external parties, in order to improve and complement their information and capabilities. At the same time, they can analyze aspects from networks other than their own, discovering new gaps that could lead to markets for exploration [Spithoven et al., 2012], or even obtain access to current technologies [van de Vrande et al., 2009]. 
The external knowledge factors will focus on the outside-in activities. Big businesses could research external knowledge to improve their capability of absorption [Spithoven et al., 2012], by selecting the information that could be useful to their company and finding a way to adapt the data to the way the business works. Also, they could complement the efforts obtained in their R\&D department with the efforts that other parties have made and create new ideas for collaborating with partners [Cheng, Huizingh, 2014].

As mentioned before, SMEs tend to be force to use external knowledge, due to the lack of certain resources. In this way, they can observe things that other businesses are doing, and obtain the necessary knowledge to create and commercialize a new product or service, without having to invest and risk so much money.

\subsubsection{Revenues factor (Inside-Out)}

Continuing with what mentioned before, in this factor are reflected the inside-out activities and the impacts that they can have on an organization. These benefit primarily those businesses that have a developed R\&D department and that are searching for improvement, or even developing different innovations that may or may not introduce in the market. With all these inventions and research, businesses can sell their knowledge, license out their products and services [Cheng, Huizingh, 2014], and maximize income by selling Intellectual properties that may not be used [Mo Ahn et al., 2016]. Chesbrough and Kardon, A. [2006] stress that companies can generate business by commercializing, along with other companies, products, services, technologies and knowledge that will not be used by the organizations.

SMEs could benefit from this by obtaining advanced information from businesses, regarding technologies that they are not capable of developing by themselves; they could create a new business for some IP or technology that a business was not using, or businesses could even discover different perspectives for working with those innovations. Enterprises can benefit from external innovation opportunities [van de Vrande et al., 2009].

\subsubsection{Resources for superior functionality factor}

Refer to superior functionality as the functions and features that a product or service could have, added to the main functionality that they should achieve for satisfying customers' needs. These features will add value and benefits, in contrast to what the customer has to exchange in order to obtain the product or service [Balaji, Kumar Roy, 2017].

As mentioned before, organizations are no longer capable of developing all the knowledge needed for creating and innovating products and services. In addition, working within their own networks would only lead to a tiny perspective, instead of searching for different 
markets and technologies. Using external knowledge for the innovation process will take the company to a higher product-service functionality that goes beyond in-house competences [Spithoven et al., 2012].

In the same way, organizations could find information not only about other businesses, but also about their own customers. Involving clients to inform the internal innovation processes could lead business organizations to meet their clients' demands, which should result in increased growth [van de Vrande et al., 2009]; with this approach, organizations could have better insights into clients' needs and develop better offerings which could turn into a perception of superior functionality [Cheng, Huizingh, 2014]. Chesbrough and Appleyard [2007] also stress that users contribute ideas and content, in a direct way, in order to improve the quality and diversity of the product. It is the business's task to understand these insights and know how to apply them to achieve successful improvement.

\subsubsection{Complementary Skills factor (Talent)}

SMEs could benefit the most from this factor. As declared before, they not only lack knowledge and technologies, but also human resources, because of their nature of being small and new. SMEs tend to have a shortage of human resources that could scan the environment (e.g. competitors, markets) in a systematic way in order to obtain the necessary knowledge [Spithoven et al., 2012]. In addition, van de Vrande, V. et al., [2009] say that when SMEs start to grow, they start to develop formal structures and, for this, they start recruiting specialized workers. Not only SMEs but also large businesses could find access to different innovation processes, in which they could develop skills by a collaboration and combination of skills and collective learning, thus obtaining what they are missing [Gronum et al., 2012; Maurer, Valkenburg, 2014].

\subsubsection{Reduction of risks factor}

According to Maurer and Valkenburg [2014], "risks are shared and the newly made partner is likely to keep a stronger interest in further project developments than a former supplier would have." Sharing risks encourages the different parties to commit to the project at hand. A company would not make the same commitment if it was simply a supplier for the other company.

On the other hand, this factor could become a demotivator if open innovation platforms do not find a way to create relationships of trust. Maurer, C. and Valkenburg, R. [2014] state that companies are looking for trust with other parties (e.g. other companies, individuals) in order to keep confidential information, instead of taking it to competitors. Businesses need to be sure that coworkers will be willing to share the necessary information for the collaboration among the parties [Maurer, Valkenburg, 2014]. 
Because of this, open innovation platforms must have the correct norms and protocols, as well as agreement among the parties involved, so that they know the shared information will be protect, and they will receive what they were expecting. Having these protocols, norms and agreements in order, businesses could find another motivation for participating in an open innovation platform.

\subsection{Universities}

Universities may have many resources to contribute to these ecosystems, but what can they find interesting about these relationships that could motivate them to engage in an open innovation ecosystem? Three main factors that could motivate universities' engagement where found:

\subsubsection{Materialize their ideas and facilitate knowledge to help society}

Universities are an important instrument to help other actors acquire new knowledge and put it into practice. They facilitate society's commitment to develop responsible people with the necessary skills to contribute to their environment.

They also provide infrastructure and technologies to low-growth societies, and boost their growth, as well as providing advice to small businesses and companies.

For the other hand, while more interaction between industry and universities, there is higher propensity to improve the status of professorial and the development of patents. [Perkmann, Walsh, 2007].

Besides, partnerships with businesses allow universities to give their students the opportunity to start working in a real-world environment where they can apply the knowledge they have been acquiring.

Universities look to give their students the opportunity to work. Platforms provide them with the opportunity to apply knowledge, science and technology developed by professors and researchers [Perkmann, Walsh, 2007].

\subsubsection{Funding and resources}

Universities are continually seeking sponsorship, be it from industrial relationships or government, and they need it to be able to develop some of their projects that they could not develop on their own.

"A number of universities have stepped up their efforts to procure service and training contracts with various government and industrial clients. The desire to generate income prompted by the move to autonomy has been the critical driver for this" [Moeliodihardjo et al., 2012]. 
Today, academics are subject to the economic and competitive factors that constrain all forms of science, including basic research. However, short-range motivation to make money should not guide universities [Nyman, 2015], meaning that universities should seek long-term relationships with industries and government. They should not look for immediate profits from these relationships, but rather the funds and resources necessary to carry out their research agenda.

Of course, this is a two-sided motivator, and the right architecture needs to be in place for it to function correctly. For example, companies must provide the right incentives to the right participants; they should understand what talented contributors find valuable about interacting with their environment. Financial incentives may be necessary in some instances [Bughin et al., 2008]. As in this case, universities are interested in some kind of financial incentive, among others, to engage in this ecosystem.

\subsubsection{External information to update internal programs}

The mainly propose of universities is to develop people with the necessary skills and knowledge to collaborate actively in society. Since industries and technologies are constantly changing, educational programs must be constantly update. This is a key factor because businesses are looking for allies in capability development [Zinser, Lawrenz, 2004].

"Some industries are experiencing a wave of employee retirements, while at the same time new technology is requiring additional training for companies to remain internationally competitive. The training is so extensive and applied to so many people that human resource development professionals are looking to outside contractors (e.g. community colleges) to help develop and provide programs" [Zinser, Lawrenz, 2004].

In this way, universities fulfill the needs of industries seeking certain talents and skills, even as they pursue their own interest in allowing their students to have better jobs, better pay, and the knowledge needed to be productive in society.

Universities have the "potential to transform the interface between science and society, but it is obstructed by institutional structures, review and reward systems, and funding mechanisms" [Whitmer et al., 2010]. Moreover, universities have been falling behind in recent years, coming to the point where their technology and knowledge is no longer at the same level as industry's. This is why universities should demonstrate their commitment to keeping up to date by investing in their own development. Adopting external information from industry can help. 


\section{Application Case}

To illustrate the text above, a case is presented where is exposed some benefits derived from the collaboration between businesses, universities and government.

As mentioned before, innovation and fast growth have led companies to change the way they do business and to look for new opportunity sectors, in order to continue being competitive with small innovative firms that are emerging [Rohrbeck et al., 2009].

The case How Deutsche Telekom creates an open innovation ecosystem, developed by Rohrbeck, R., Gemuenden, K. and Hölzle, H. [2009], is based on the case of Deutsche Telekom, a telecommunications firm that uses an open innovation ecosystem to integrate and facilitate the innovation process in the company. Its goal was to start developing an open innovation ecosystem in response to new firms' ability to achieve fast growth. They started to work in cooperation and competitively with other businesses and universities. In order to achieve that, they work with four main processes: idea generation, where they aim to produce innovation; research, where they collaborate with universities; development, where they co-create with external partners to create new products/services; and commercialization, where they also engage with outside partners to take the new developments out into the market.

As mentioned, the case explains how this telecommunications business takes advantage of the open innovation ecosystem, how it works with its different partners and what it obtains through those collaborations.

First, the relationship with businesses. Deutsche Telekom has worked with other companies, operating with their innovations and acquiring more innovative services and products using the knowledge of other companies who were their suppliers, such as Alcatel-Lucent, Ericsson and Nokia Siemens Networks. This relates to what was presented in the first and fourth factor that can be motivators for businesses, External Knowledge: Outside-in and Resources for superior functionality, it stated that businesses would have better functionality in their products and services using external knowledge, in contrast to just using in-house capabilities and know-how. With this, they would be able to complement their information for developing new things. In addition, they generate workshops with other partners for sharing knowledge, without having the fear that their information could be exploited.

Additionally, Deutsche Telekom's main effort in terms of collaborations with other partners has been in Research and Development, looking to share risks and costs when developing a new product or service. The fifth factor of motivator for businesses affirms this, where it was express that businesses use other organizations' technologies, which have been prove, in order to reduce risks. 
Deutsche Telekom has been using T-Labs, which are research centers provided by the universityindustry relationship. "Within T-Labs' four endowed chairs, over 80 post-doctoral researchers and over 100 Deutsche Telekom employees are working on technology and customer-driven innovation." [Rohrbeck et al., 2009]. In order for this to work correctly, they provide an adequate organizational structure for academics and corporate R\&D staff to collaborate. Here, they work with postdoctoral researchers, who are usually still connected with their home universities, creating an informal network where they can validate their research activities. Plus, their latent link with their universities allows them to hire $\mathrm{PhD}$ students from it to help with the research.

It is observe that the universities that they work with, which are the Technical University of Berlin, and three Fraunhofer Institutes for applied research, have two principal motivators to engage with Deutsche Telekom, as seen in the theory. The first one is professorial status and involvement in patenting, since postdoctoral researchers are involved in the company's innovation process. The second one is the work opportunity for $\mathrm{PhD}$ students, where they can learn and interact with a real innovation and development environment where they can grow and learn specific competences.

Taking advantage of another important touchpoint with universities, Deutsche Telekom is participating in executive forums such as the Münchner Kreis or the Feldafinger Kreis, which bring together academics and executives to discuss topics like digital rights or the future of the Internet. This allows Deutsche Telekom to obtain important information for its innovation process, and at the same time it allows academics (universities) to speak their minds and be hear in order to watch their ideas be applied, which is the first motivator mentioned in the theoretical framework.

Finally, the case establishes the relationship Deutsche Telekom has with the government. Based on the first phase of the innovation process, the company began by participating in external forums, which served as facilitators for networking between leading businesses and universities, creating spaces to discuss and panels to collaborate, all with the intention of exploring strategic innovation areas. Furthermore, the company got involved in government-sponsored activities including discussions and innovation activities between the CEO's of the largest companies in Germany and leading academics.

The government's main objective is to present transparency, to facilitate and to motivate the participation of the citizens, companies and the society in general. As observed in the Deutsche Telekom Company, the government was not directly involved; in other words, it was just an indirect player in the ecosystem, presenting its resources at forums and sponsored activities, 
encouraging open participation and collaborations among stakeholders, and helping to generate connections and share ideas, as Lee, G. and Kwak, Y. H. [2011] stated. It was perceive the representation of the government's motivations to participate in an open innovation ecosystem in the case.

\section{Conclusion}

As seen in the case of Deutsche Telekom, the main actors chose to analyze through this paper - government, businesses, and universities - are involved in the innovation ecosystem and actively participate and interact with each other to obtain mutual benefits.

It is important to remember that there are more actors that can be involved in an innovation ecosystem, such as society, customers, among others. However, the focus was on the three mentioned before due to the impact they have on the economy, society, and the organization's, businesses' and citizens' participation.

For each of these actors different factors are found that could motivate them to participate in this ecosystem. These motivators facilitate the exchange and use of resources, information and knowledge among the actors in order for them to keep up with the continuous growth of technologies and innovation, even though they might not have the adequate tools and means to develop new ideas, products and services by themselves, making special reference to universities and businesses. This was analyze through the perspective where the government can be an intermediator interested in the engagement of the different actors who, with their different discoveries and developments, can help society. In addition, the government should promote openness and transparency in order to create a more secure ecosystem and encourage businesses and universities to participate in it.

Finally, this research leads to keep investigating the impact that innovation ecosystems are having around the world and among other entities. As found, this model is popular with big businesses due to the benefits that it has for them, inducing curiosity in us about why independent actors who have different objectives participate in order to obtain benefits from this model. 


\section{Bibliography:}

1. Adner Ron (2006), Match your innovation strategy to your innovation ecosystem, Harvard business review, 84[4], 98.

2. Akaka Melissa, Vargo Stephen (2014), Technology as an Operant Resource in Service [Eco] Systems, Information Systems and E-Business Management 12: 367-84. https://doi.org/10.1007/s10257-013-0220-5

3. Antikainen Maria, Ahonen Mikko (2010), Motivating and Supporting Collaboration in Open Innovation, European Journal of Innovation Management, 21. https://doi.org/10.1108/14601061011013258

4. Aris Norma, (2007), SMES: Building Blocks for Economic Growth, Department of Statistics Malaysia.

5. Autio Erkko, Thomas Llewellyn (2014), Innovation ecosystems, The Oxford handbook of innovation management, 204-288. https://doi.org/10.1093/oxfordhb/9780199694945.013.012

6. Balaji M. S., Kumar Roy, S. (2017), Value co-creation with Internet of things technology in the retail industry, Journal of Marketing Management, 33[1-2], 7-31. https://doi.org/10.1080/0267257X.2016.1217914

7. Battistella Cinzia, Felice De Toni Alberto, Pessot Elena, (2017), Practising Open Innovation: A Framework of Reference, Business Process Management Journal 23: 1311-36. https://doi.org/10.1108/BPMJ-10-2016-0219

8. Bughin Jacques, Chui Michael, Johnson Brad (2008), The next step in open innovation, The McKinsey Quarterly, 4[6], 1-8.

9. Carayannis Elias G., Campbell David F.J. (2012), Mode 3 knowledge production in quadruple helix innovation systems, In Mode 3 knowledge production in quadruple helix innovation systems [pp. 1-63]. Springer, New York, NY.

https://doi.org/10.1007/978-1-4614-2062-0

10. Chaminade Chaminade, Edquist Charles (2006), From theory to practice: the use of the systems of innovation approach in innovation policy, Innovation, science, and institutional change, 141-160.

11. Cheng Collin C. J., Huizingh Eelko K. R. E. (2014), When is Open Innovation Beneficial? The Role of Strategic Orientation, The Journal of Product Innovation Management, 31[6], 1235-1253. https://doi.org/10.1111/jpim.12148

12. Chesbrough Henry W. (2006), Open innovation: The new imperative for creating and profiting from technology, Harvard Business Press.

13. Chesbrough Henry W., Appleyard Melissa M. (2007), Open Innovation and Strategy, California Management Review, 50[1], 57-76. https://doi.org/10.2307/41166416 
14. Chesbrough Henry W., Kardon Adrienne C. (2006), Beyond High tech: early adopters of open innovation in other industries, R\&D Management, 36[3], 229-236. https://doi.org/10.1111/j.1467-9310.2006.00428.x

15. Etzkowitz Henry (2011), The Triple Helix of University - Industry - Government, Science Policy Institute, 18.

16. European Commission (2009), European innovation scoreboard 2009, Brussels: European Commission

17. Feld Brad (2012), Startup communities: building an entrepreneurial ecosystem in your city, John Wiley \& Sons, Hoboken. https://doi.org/10.1002/9781119204459

18. Fuerlinger George, Fandl Ulrich, Funke Thomas (2015), The role of the state in the entrepreneurship, Triple Helix, 26. https://doi.org/10.1186/s40604-014-0015-9

19. Gawer Annabelle, Cusumano Michael A. (2014), Industry Platforms and Ecosystem Innovation, Journal of Product Innovation Management 31: 417-33 https://doi.org/10.1111/jpim.12105

20. Gronum Sarel, Verreynne Martie-Louise, Kastelle Tim (2012), The Role of Networks in Small and Medium-Sized Enterprise Innovation and Firm Performance, Journal of Small Business Management, 50[2], 257-282. https://doi.org/10.1111/j.1540-627X.2012.00353.X

21. Harrison Teresa M., Pardo Theresa A., Cook Meghan (2012), Creating Open Government Ecosystems: A Research and Development Agenda. University of Albany, 29.

22. Holbrook Morris B. (1987), What is consumer research?, Journal of Consumer Research, 14[1], pp.128-132. https://doi.org/10.1086/209099

23. Iansiti Marco, Levien Roy (2004), The keystone advantage: what the new dynamics of business ecosystems mean for strategy, innovation, and sustainability, Harvard Business Press.

24. Lathrop Daniel, Ruma Laurel (2010), Open Government: Collaboration, Transparency, and Participation in Practice, O'Reilly Media, Inc.

25. Lee Gwanhoo, Kwak Young Hoon (2011), An Open Government Implementation Model: Moving to Increased Public Engagement, IBM Center for The Business of Government, 37. https://doi.org/10.1145/2037556.2037598

26. Lusch Robert F., Nambisan Satish (2015), Service innovation: A service-dominant logic perspective, MIS quarterly, 39[1], 155-175. https://doi.org/10.25300/MISQ/2015/39.1.07

27. Lusch Robert, Nambisan Satish (2015), Service Innovation: A Service-Dominant Logic Perspective, MIS Quarterly 39: 155-76. https://doi.org/10.25300/MISQ/2015/39.1.07

28. Markkula Markku, Kune Hank (2015]), Making smart regions smarter: smart specialization and the role of universities in regional innovation ecosystems, Technology Innovation Management Review, 5[10]. https://doi.org/10.22215/timreview932 
29. Maurer Christiane, Valkenburg Rianne (2014), Approaches to a Networked Innovation, International Journal of Innovation \& Technology Management, 11[1], 144004[1-18]. https://doi.org/10.1142/S0219877014400045

30. Ahn Joon M., Ju Yonghan, Moon Tae H., Minshall Timothy, Probert David, Sohn So Y., Mortara Letizia (2016), Beyond absorptive capacity in open innovation process:

the relationships between openness, capacities and firm performance,

Technology, Analysis \& Strategic Management, 28[9], 1009-1028.

https://doi.org/10.1080/09537325.2016.1181737

31. Moeliodihardjo Bagyo Y., Soemardi Biemo W., Brodjonegoro Satryo S., Hatakenaka Sachi (2012), University, industry, and government partnership: Its present and future challenges in Indonesia, Procedia-Social and Behavioral Sciences, 52, 307-316. https://doi.org/10.1016/j.sbspro.2012.09.468

32. Nyman Göte S. (2015), University-business-government collaboration: from institutes to platforms and ecosystems, Triple Helix, 2[1], 2. https://doi.org/10.1186/s40604-014-0014-X

33. Perkmann Markus, Walsh Kathryn (2007), University-industry relationships and open innovation: Towards a research agenda, International Journal of Management Reviews, 9[4], 259-280. https://doi.org/10.1111/j.1468-2370.2007.00225.x

34. Rayna Thierry, Striukova Ludmila, Darlington John (2015), Co-Creation and User Innovation: The Role of Online 3D Printing Platforms, Journal of Engineering and Technology Management 37: 90-102. https://doi.org/10.1016/j.jengtecman.2015.07.002

35. Rayna Thierry, Striukova Ludmila (2015), Open Innovation 2.0: Is Co-Creation the Ultimate Challenge?, International Journal of Technology Management 69: 38-53. https://doi.org/10.1504/IJTM.2015.071030

36. Rohrbeck René, Hölzle Katharina, Gemuenden Hans G. (2009), How Deutsche Telekom creates an open innovation ecosystem, R\&D Management, 39[4], 420-430. https://doi.org/10.1111/j.1467-9310.2009.00568.x

37. Romero David, Molina Arturo (2009), Value Co-Creation and Co-Innovation: Linking Networked Organisations and Customer Communities, In , 401-12. Springer. https://doi.org/10.1007/978-3-642-04568-4_ 42

38. Sedera Darshana, Lokuge Sachithra, Grover Varun, Sarker Suprateek, Sarker Saonee (2016), Innovating with Enterprise Systems and Digital Platforms: A Contingent Resource-Based Theory View, Information \& Management 53: 366-79.

https://doi.org/10.1016/j.im.2016.01.001 
39. Spitoven Andre, Vanhaverbeke Wim, Roijakkers Nadine (2012), Open Innovation Practices in SMEs and large enterprises, Small Business Economics, 41[3], 537-562. https://doi.org/10.1007/s11187-012-9453-9

40. Storbacka Kaj, Roderick J. Brodie, Böhmann Tilo, Maglio Paul P., Nenonen Suvi (2016), Actor Engagement as a Microfoundation for Value Co-Creation, Journal of Business Research 69: 3008-17. https://doi.org/10.1016/j.jbusres.2016.02.034

41. Van de Vrande Vareska, de Jong Jeroen P. J., Vanharvebeke Wim, de Rochemont Maurice (2009), Open Innovation in SMEs: Trends, motives and management challenges, Elsevier Technovation, 29, 423-437. https://doi.org/10.1016/j.technovation.2008.10.001

42. Vargo Satish L., Lusch Robert F. (2006), Service-dominant logic. The service-dominant logic of marketing: Dialog, debate, and directions.

43. Whitmer Ali, Ogden Laura, Lawton John, Sturner Pat, Groffman Peter M. (2010), The engaged university: providing a platform for research that transforms society, Frontiers in Ecology and the Environment, 8[6], 314-321. https://doi.org/10.1890/090241 44. Zinser Richard, Lawrenz Frances (2004), New roles to meet industry needs: A look at the Advanced Technological Education program, Journal of Vocational Education Research, 29[2], 85-99. https://doi.org/10.5328/JVER29.2.85 